\title{
Development of a radiolabeled caninized anti-EGFR antibody for comparative oncology trials
}

\author{
Judit Fazekas-Singer ${ }^{1,2}$, Neydher Berroterán-Infante ${ }^{3,4}$, Christina Rami-Mark ${ }^{2,3,4}$, \\ Monika Dumanic ${ }^{3}$, Miroslawa Matz ${ }^{2}$, Michael Willmann'5, Fritz Andreae ${ }^{6}$, Josef \\ Singer ${ }^{2,3,7}$, Wolfgang Wadsak ${ }^{3,4,8}$, Markus Mitterhauser ${ }^{3,9}$ and Erika Jensen- \\ Jarolim ${ }^{1,2}$ \\ ${ }^{1}$ Comparative Medicine, The Interuniversity Messerli Research Institute of the University of Veterinary Medicine Vienna, \\ Medical University Vienna, and University of Vienna, Vienna, Austria \\ ${ }^{2}$ Institute of Pathophysiology and Allergy Research, Center of Pathophysiology, Infectiology and Immunology, Medical \\ University of Vienna, Vienna, Austria \\ ${ }^{3}$ Department of Biomedical Imaging and Image-Guided Therapy, Division of Nuclear Medicine, Medical University of Vienna, \\ Vienna, Austria \\ ${ }^{4}$ Institute of Inorganic Chemistry, University of Vienna, Vienna, Austria \\ ${ }^{5}$ Department for Companion Animals and Horses, University of Veterinary Medicine Vienna, Vienna, Austria \\ ${ }^{6}$ piCHEM Forschungs- und Entwicklungs GmbH, Graz, Austria \\ ${ }^{7}$ Department of Internal Medicine II, University Hospital Krems, Karl Landsteiner University of Health Sciences, Krems an \\ der Donau, Austria \\ ${ }^{8} \mathrm{CBmed} \mathrm{GmbH}-$ Center for Biomarker Research in Medicine, Graz, Austria \\ ${ }^{9}$ LBI Applied Diagnostics, Vienna, Austria \\ Correspondence to: Erika Jensen-Jarolim, email: erika.jensen-jarolim@meduniwien.ac.at \\ Keywords: epidermal growth factor receptor, radio-immunotherapy, canine mammary carcinoma, canine antibody, comparative \\ oncology \\ Received: August 02, $2017 \quad$ Accepted: August 23, $2017 \quad$ Published: September 15, 2017 \\ Copyright: Fazekas-Singer et al. This is an open-access article distributed under the terms of the Creative Commons Attribution \\ License 3.0 (CC BY 3.0), which permits unrestricted use, distribution, and reproduction in any medium, provided the original author \\ and source are credited.
}

\section{ABSTRACT}

Due to large homology of human and canine EGFR, dogs suffering from spontaneous EGFR+ cancer can be considered as ideal translational models. Thereby, novel immunotherapeutic compounds can be developed for both human and veterinary patients. This study describes the radiolabeling of a canine anti-EGFR IgG antibody (can225IgG) with potential diagnostic and therapeutic value in comparative clinical settings. Can225IgG was functionalized with DTPA for subsequent chelation with the

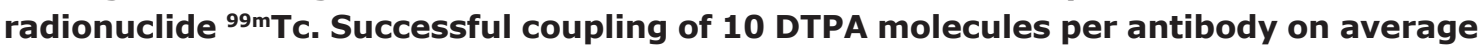
was proven by significant mass increase in MALDI-TOF spectroscopy, gel electrophoresis and immunoblots. Following functionalization and radiolabeling, ${ }^{99 \mathrm{~m}}$ TC-DTPA-can $225 \mathrm{IgG}$ fully retained its binding capacity towards human and canine EGFR in flow cytometry, immuno- and radioblots, and autoradiography. The affinity of radiolabeled can225IgG was determined to $K_{D} 0.8 \pm 0.0031 \mathrm{nM}$ in a real-time kinetics assay on canine carcinoma cells by a competition binding technique. Stability tests of the radiolabeled compound identified TRIS buffered saline as the ideal formulation for short-term storage with $\mathbf{8 7 . 1 1} \pm \mathbf{6 . 0 4 \%}$ intact compound being still detected 60 minutes post radiolabeling. High stability, specificity and EGFR binding affinity pinpoint towards ${ }^{99 \mathrm{~m} T c}$-radiolabeled can225IgG antibody as an ideal lead compound for the first proof-of-concept diagnostic and therapeutic applications in canine cancer patients. 


\section{INTRODUCTION}

Detection of primary and secondary malignant lesions in clinical oncology currently largely depends on tracking of the first steps in glycolysis in metabolically active tissue via 2-deoxy-2-[18 F]fluoro-D-glucose $\left(\left[{ }^{18} \mathrm{~F}\right] \mathrm{FDG}\right)$ in PET or PET/CT $[1,2]$. Under certain circumstances, this method can display false positive results, e.g. in inflamed tissue [3] or highly metabolizing healthy tissues like brain or liver [4].

Therefore, tumor specific detection with monoclonal antibodies targeting tumor-associated antigens (TAAs) offers an ideal, refined target for novel therapeutic and diagnostic (=theranostic) strategies. One of the most thoroughly investigated TAAs is the epidermal growth factor receptor-1 (EGFR). EGFR-overexpression is reported amongst others in colorectal cancer or carcinomas of the head and neck region and highly successfully targeted by specific immunotherapy with the monoclonal antibody cetuximab [5]. Besides the diagnostic potency of radiolabeled antibodies, their therapeutic value in cancer has been recognized under the concept of theranostics [6].

Mouse models often lack important features of cancer such as genomic instability or tumor heterogeneity and do not ideally mimic human pharmacokinetics, which may cause failure in subsequent clinical trials [7]. To overcome this problem, this study relies on the concept of "comparative oncology" in order to gain more reliable pre-clinical data for human studies from real life cancer in pets. Of equal importance, comparative oncology aims to simultaneously develop active compounds for veterinary oncology and to test these compounds in veterinary clinical trials [8] which, interestingly, fall under directives for animal experiments in the EU as well as in the US [9].

To overcome these issues, dog models offer a new perspective for cancer therapy development. Moreover, dogs suffer from cancer with similar incidence rates as humans, share the same risk factors as their owners and have a strikingly similar immune system, thus, providing suitable models for human malignant diseases $[10,11]$. On the other hand, diagnostic and therapeutic options are currently still very limited for animal patients and thus there is an urgent need for the development of speciesspecific targeted therapies.

While some canine TAAs as CEA substantially differ from the human counterpart [12], members of the EGFR family share an outstanding homology of up to $95 \%$ [13]. Therefore, the canine EGFR, expressed by canine cancer cells, could be targeted by cetuximab which led to tumor growth inhibition, similarly to the effects observed on human cancer cells [13].

Nevertheless, dog tumor patients cannot be treated with cetuximab $[14,15]$ as this human-mouse chimeric antibody would be regarded as foreign by the canine immune system and lead to specific hypersensitivity. This prompted us previously to generate a caninized version of cetuximab by fusing the variable regions of its murine precursor to canine constant gamma-regions [16]. Like cetuximab, this newly generated antibody "can225IgG" elicited tumor cell growth inhibition in vitro. Moreover, via its constant domain, can225IgG could bind to Fcyreceptors of canine immune cells and thereby mediate antibody-dependent cellular cytotoxicity (ADCC) and phagocytosis (ADCP) of EGFR+ tumor cells [16].

This antibody served as lead compound in the present study, however, lacking a binding residue for a radiometal for diagnostic use. Therefore, a modification was done by functionalization of the multiple lysine residues with diethylene-triamine-pentaacetic acid (DTPA), to enable a subsequent radio-labeling with the metastable form of technetium- $99\left({ }^{99 \mathrm{~m}} \mathrm{Tc}\right)$ for visualization in single photon emission computed tomography (SPECT). Although there are human clinical trials ongoing on tumor imaging using anti-EGFR-antibodies labeled with diagnostic nuclides $\left(\left[{ }^{89} \mathrm{Zr}\right] \mathrm{Zr}\right.$-cetuximab: NCT00691548 (completed), NCT01691391 (recruiting), $\left[{ }^{68} \mathrm{Ga}\right]$ Ga-EGFR-affibody: NCT02916329 (recruiting), [ ${ }^{125}$ I]I-MAB425: NCT01317888 (status unknown)) [17], none of these antibodies is FDA-approved yet, nor are they exploiting the full potency of radiolabeled antibodies in terms of therapeutic nuclides. Therefore, by testing the stability and specificity of this newly labeled ${ }^{99 \mathrm{~m}} \mathrm{Tc}$ DTPA-can225IgG construct in vitro, our study could contribute to the establishment of new imaging options in veterinary clinical oncology by introducing highly specific monoclonal antibodies as novel tracers for diagnosis in veterinary malignant diseases. In the specific case of canine osteosarcoma for instance, the early detection of distant metastases by a radiolabeled antiEGFR antibody may considerably influence and improve therapeutic decisions. Furthermore, successfully applied diagnostic monoclonal antibodies could also be labeled with therapeutic radionuclides and thus represent a novel category of therapeutic options in veterinary oncology.

\section{RESULTS}

\section{DTPA functionalization of can225IgG}

The dog-mouse chimeric anti-EGFR antibody can225IgG (Figure 1A) was functionalized with S-2-(4isothiocyanatobenzyl)-diethylene-triamine-pentaacetic acid (p-SCN-Bn-DTPA, in following 'DTPA'; Figure 1B) for subsequent ${ }^{99 \mathrm{~m}} \mathrm{Tc}$-radiolabeling. DTPA can be covalently coupled to potentially all lysine residues of the monoclonal antibody. The heavy chain of can225IgG comprises 24, the light chain 9 lysine residues (Table 1). This results in 66 potential functionalization sites per antibody molecule. Nevertheless, not each lysine is functionalized due to sterical hindrance. In order to determine the optimal reaction conditions, 3 different experimental settings (E1-3) were tested. 
A

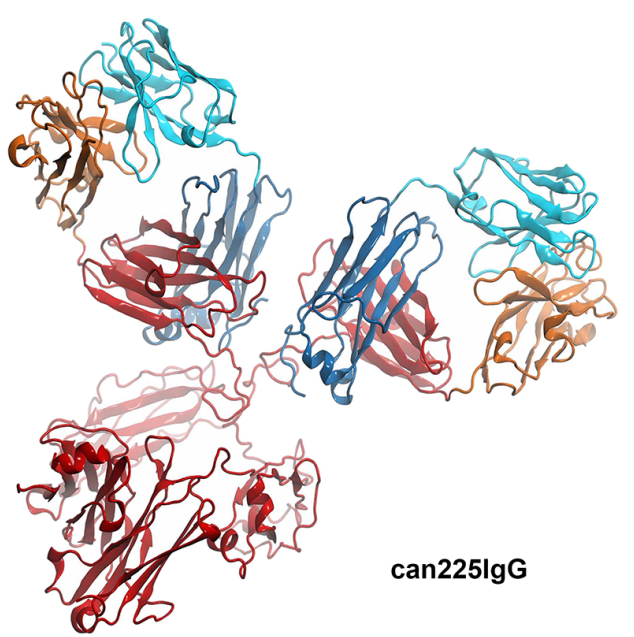

C

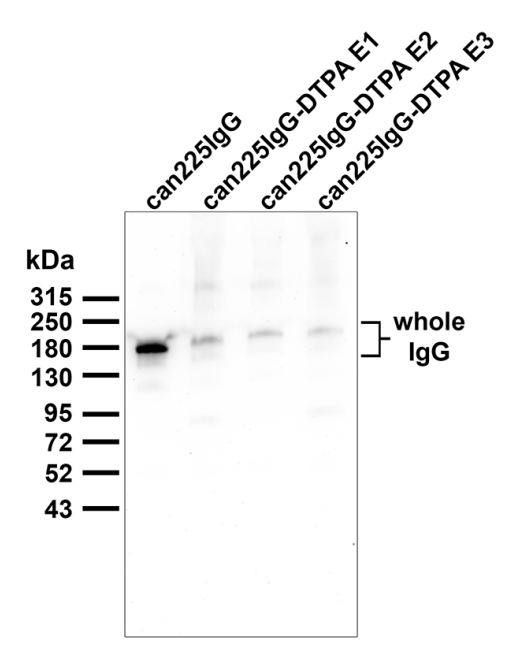

$E$

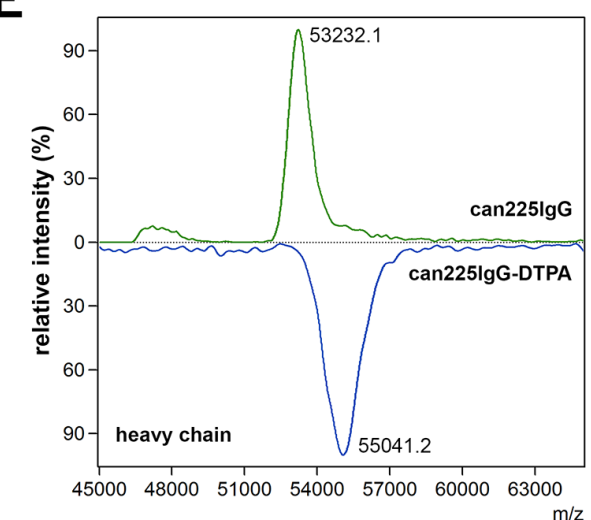

B

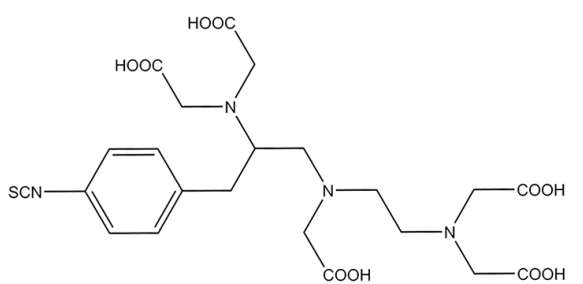

p-SCN-Bn-DTPA
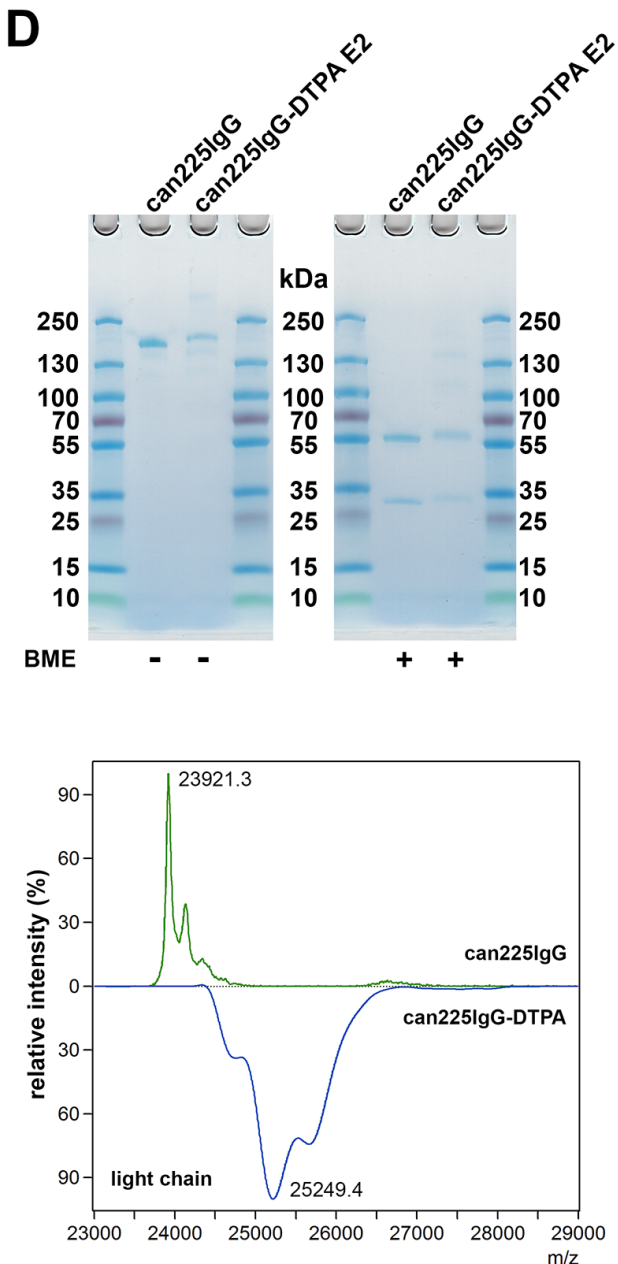

Figure 1: Functionalization of can225IgG with DTPA. (A) In silico model of can225IgG (Model generation described in ref. 12). (B) Molecular structure of p-SCN-Bn-DTPA used for the functionalization of can225IgG. (C) Western blot with unmodified (lane 1) and DTPA-conjugated can225IgG variants E1-E3 (lanes 2-4) loaded as samples and detected with anti-dog IgG HRP. (D) SDS-PAGE with unmodified (lane 2) and DTPA-conjugated can225IgG E2 (lane 3) visualizing mass increase of the whole antibody (left panel) and both heavy and light chains under reducing conditions (right panel) upon functionalization. BME - 2-mercaptoethanol. (E) MALDI-TOF mass spectra of DTT-treated unmodified can225IgG (upper panels) and DTPA-conjugated can225IgG E2 (lower panels) 
Table 1: Potential functionalization sites of can225IgG

\begin{tabular}{lcc}
\hline Chain & Lysine residues & Amino acid sequence \\
\hline can225 gamma & 24 & QVQLKQSGPGLVQPSQSLSITCTVSGFSLTNYGVHWVRQSPGKG \\
& LEWLGVIWSGGNTDYNTPFTSRLSINKDNSKSQVFFKMNSLQSN \\
& DTAIYYCARALTYYDYEFAYWGQGTLVTVSAASTTAPSVFPLAP \\
& SCGSQSGSTVALACLVSGYIPEPVTVSWNSGSLTSGVHTFPSIL \\
& QSSGLYSLSSMVTVPSSRWPSETFTCNVAHPATNTKVDKPVVKE \\
& CECKCNCNNCPCPGCGLLGGPSVFIFPPKPKDILVTARTPTVTC \\
& VVVDLDPENPEVQISWFVDSKQVQTANTQPREEQSNGTYRVVSV \\
& LPIGHQDWLSGKQFKCKVNNKALPSPIEEIISKTPGQAHQPNVY \\
& VLPSRDEMSKNTVTLTCLVKDFFPPEIDVEWQSNGQQEPESKYRMTP \\
& PQLDEDGSYFLYSKLSVDKSRWQRGDTFICAVMHEALHNH \\
can225 kappa & YTQKSLSHSPGK \\
& DILLTQSPVILSVSPGERVSFSCRASQSIGTNIHWYQQRTNGS \\
& PRLLIKYASESISGIPSRFSGSGSGTDFTLSINSVESEDIADY \\
& ASVVCLLNSFYPKDINVKWKVDGVIQDTGIQESVTEQDKDSTY \\
& SLSSTLTMSSTEYLSHELYSCEITHKSLPSTLIKSFQRSECQRVD
\end{tabular}

Lysine residues $(\mathrm{K})$ are highlighted in red; amino acids in bold format constitute the variable region of the respective antibody chain.

DTPA-can225IgG E1 was labeled with 25x molar excess of DTPA, E2 and E3 with 50x molar excess, but at different $\mathrm{pH}$ levels. All three experimental reaction conditions resulted in a molecular weight gain of the antibody (Figure 1C). Conditions E2 and E3 displayed more weight increase compared to E1. As in condition E3 more degraded bands were visible too, condition E2 was regarded best and thus chosen for subsequent experiments.

Both heavy and light chains of DTPA-can225IgG E2 were functionalized with DTPA, determined by polyacrylamide gel electrophoresis (PAGE, see Figure 1D) and matrix-assisted laser desorption ionization - time of flight (MALDI-TOF) mass spectrometry (Figure 1E). The average mass increase (calculated from the major peaks of the heavy and light chains) was $1809 \mathrm{Da}$ for the heavy and $1328 \mathrm{Da}$ for the light chain, accounting for approximately 10 DTPA molecules (FW: $649.9 \mathrm{~g} / \mathrm{mol}$ ) per antibody.

\section{Specificity assessment after functionalization and ${ }^{99 \mathrm{~m}} \mathrm{Tc}$ radiolabeling of can $225 \mathrm{IgG}$}

Since DTPA has a several times higher molecular mass than an amino acid, it seemed likely that functionalization in the variable region might negatively influence the specificity and affinity of the antibody towards EGFR. Therefore, it was essential to re-evaluate specificity upon DTPA-conjugation and radiolabeling. First, all 3 DTPA-conjugated variants were tested head to head with the original antibody on a preparative western blot. Here, all tested specimens retained their reactivity towards EGFR (Figure 2A).

Next, binding properties to native EGFR on the surface of cancer cells was investigated via flow cytometry. On endogenously high EGFR expressing A431 cells (Figure 2B), all 3 functionalized antibody probes bound to EGFR to the same extent as the positive control can225IgG (median fluorescence intensities: can225 IgG 125; E2 128; E3 132), only sample E1 showed slightly less binding (median fluorescence intensity 85.3) than the others. However, this observation of slightly reduced staining could not be detected in EGFR ${ }^{\text {lo }}$ HEK293T cells. Here, all 3 functionalized antibody specimens stained with comparable fluorescence intensity (Figure 2C). As anticipated, none of the antibodies (original or modified) bound to the EGFR negative cell line CHO-K1 (Figure 2D). Since variant E2 appeared to be optimal in assays investigating specificity as well, we decided to perform all subsequent radiolabeling experiments with this compound.

${ }^{99} \mathrm{~m}$ Tc-labeling resulted in a mean radiochemical yield of $44.34 \% \pm 15.28$ and a mean specific radioactivity of $3707 \mathrm{GBq} / \mu \mathrm{mol}$ (Table 2). Metal complexation may lead to a significant change in the pharmacological properties of an antibody; therefore we re-evaluated the specificity of ${ }^{99 \mathrm{~m}} \mathrm{Tc}-\mathrm{DTPA}-\mathrm{can} 225 \mathrm{IgG}$ on a radioblot. 99m Tc-DTPA-can225IgG (E2) successfully detected recombinant soluble canine EGFR and recombinant soluble human EGFR, but did not bind to another member of the human epidermal growth factor receptor family, HER-2 (Figure 2E). Interestingly, the in-house produced canine EGFR detected by ${ }^{99 \mathrm{~m}}$ Tc-DTPA-can $225 \mathrm{IgG}$ showed a less intense band on the blot compared to the commercially available human EGFR. This effect was reproducible when repeating the experiment and could not be traced back to uneven loading. To affirm that the epitope specificity of the radiolabeled antibody stayed unchanged, we performed a blocking experiment by pre- 
A

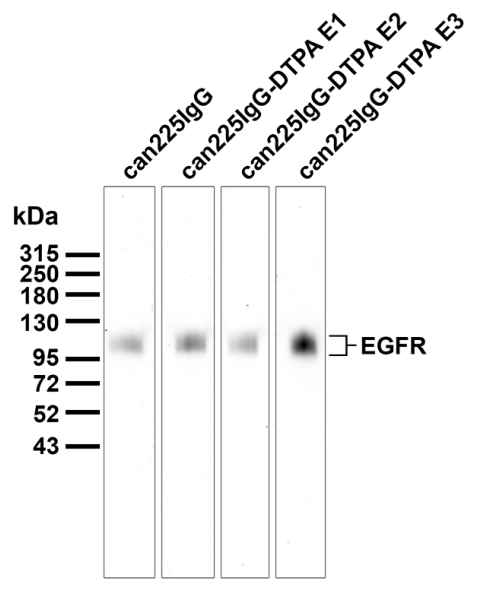

C

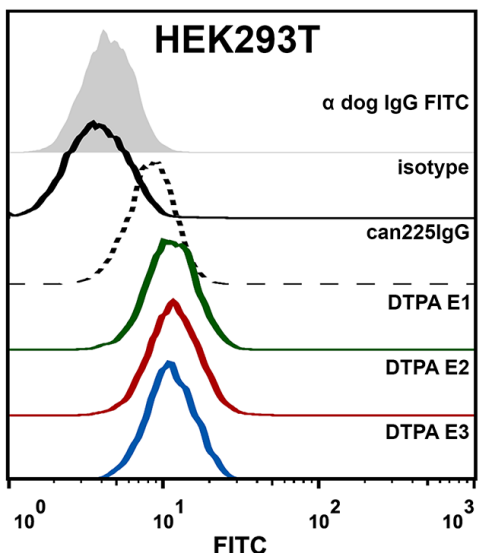

E

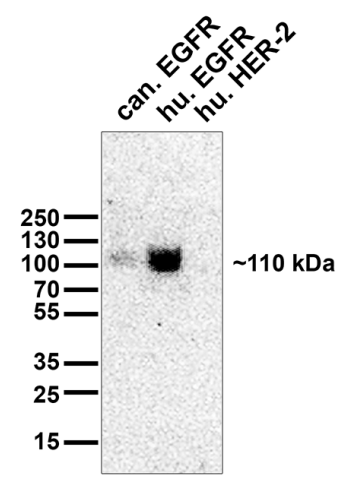

B

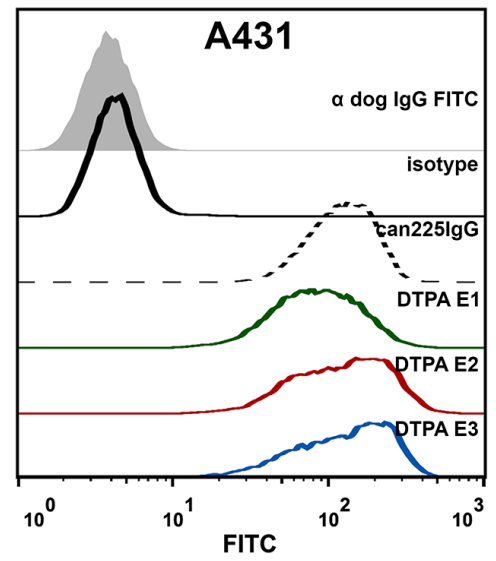

D

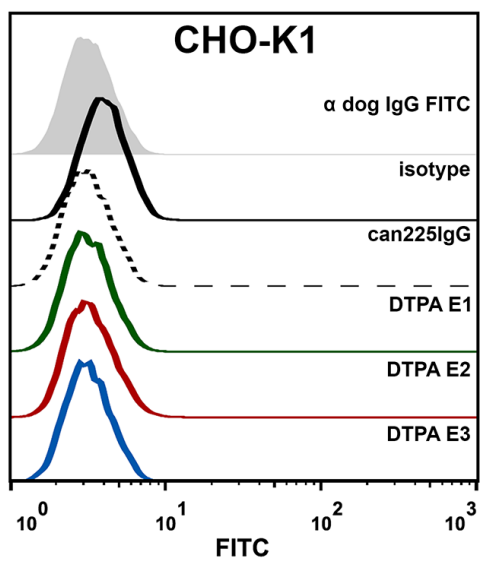

$\mathbf{F}$

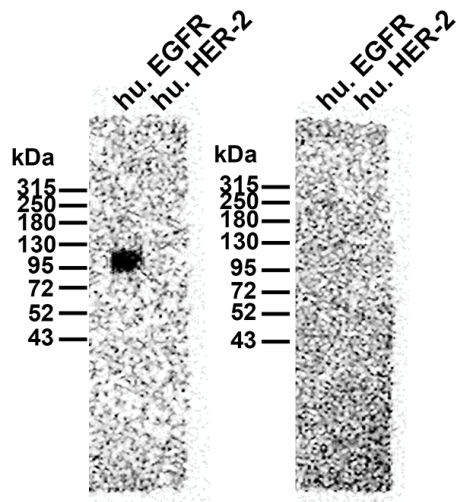

Figure 2: Specificity of DTPA-conjugated can225IgG variants E1-E3. (A) Western blot with soluble recombinant human EGFR as sample, detected with unmodified (lane 1) or DTPA-conjugated can225IgG variants E1-E3 (lanes 2-4), followed by anti-dog IgG HRP. (B) Flow cytometric binding analysis of unmodified can225IgG versus DTPA-conjugated can225IgG variants on EGFR-overexpressing A431 cells, detected by FITC-conjugated anti-dog IgG. (C) Flow cytometric binding analysis of unmodified can225IgG versus DTPAconjugated can225IgG variants on moderately EGFR-expressing HEK293T cells. (D) Flow cytometric binding analysis of unmodified can225IgG versus DTPA-conjugated can225IgG variants on EGFR negative CHO-K1 cells. (E) Radioblot with canine EGFR, human EGFR and human HER-2, detected with ${ }^{99 \mathrm{~m} T c-D T P A-c a n} 225 \mathrm{IgG}$. (F) Left panel: radioblot with human EGFR and human HER-2, detected with ${ }^{99 \mathrm{~m} T c-D T P A-c a n} 225 \mathrm{IgG}$, right panel: radioblot with human EGFR and human HER-2, pre-blocked with $10 \mu \mathrm{g} / \mathrm{ml}$ unlabeled can $225 \mathrm{IgG}$ and subsequently detected with ${ }^{99 m}$ Tc-DTPA-can225IgG. 
Table 2: Summary of radiolabeling reactions of ${ }^{99 \mathrm{~m}}$ Tc-DTPA-can225IgG

\begin{tabular}{lccccc}
\hline & $\mathbf{n}$ & Unit & Mean & SD & Median \\
\hline Starting activity & 13 & $\mathrm{GBq}$ & 0.96 & 0.41 & 1.07 \\
Product activity & 13 & $\mathrm{GBq}$ & 0.35 & 0.19 & 0.42 \\
Yield (decay corrected to start) & 13 & $\%$ & 44.34 & 15.28 & 47.86 \\
Product concentration & 5 & $\mathrm{nM}$ & 59.59 & 19.79 & 56.23 \\
Total volume of product & 5 & $\mathrm{ml}$ & 2.96 & 1.13 & 3.00 \\
Specific activity & 5 & $\mathrm{GBq} / \mu \mathrm{mol}$ & 3707 & 1778 & 2816 \\
\hline
\end{tabular}

$\mathrm{n}$ - number of experiments analyzing the depicted parameter.

incubation one of two identical membranes with cold (non-radioactive), unmodified can225IgG. ${ }^{99 \mathrm{~m}} \mathrm{Tc}-\mathrm{DTPA}-$ can225IgG specifically detected EGFR on the non-blocked blot corresponding to the results in Figure 2E. The blocked blot, however, was lacking the signal at the EGFR band, further demonstrating that the radio-compound preserved its epitope-specificity (Figure 2F).

\section{Radio- and protein stability of ${ }^{99 \mathrm{~m}}$ Tc-DTPA- can225IgG}

The major aim of our study was to develop a diagnostic compound for potential in vivo use in canine cancer patients. Accordingly, we intended to identify the ideal formulation that guarantees sufficient stability for the interval between radiolabeling and intravenous application (bolus of 1-3 ml). Under optimal conditions, we expected an interval of 45-70 minutes from quality control-release of the radiolabeled antibody until administration; in fact, we tested stability of the antibody for up to 4 hours in order to gain a more detailed picture on its pharmacokinetic stability. We assessed the amount of intact radiolabeled antibody formulated in TRIS-buffered saline (TBS, $\mathrm{pH}$ 7.4), $0.9 \% \mathrm{NaCl}, \mathrm{NaOAc}(100 \mathrm{mM}) \mathrm{pH} 6.0$ or $\mathrm{pH} 7.0$, respectively.

As pre-experiments had shown poor stability in phosphate buffered saline (PBS, pH 6.0 and 8.0) we discontinued stability testing with this buffer and did not include it in statistical tests (Figure 3A, dotted lines).

We could not observe any statistically significant difference between the other four tested formulations up to an incubation time of at least $3 \mathrm{~h}$ (Figure 3A). At 60 minutes after radiolabeling, a likely time point for administration to the patient, still $87.11 \%$ of ${ }^{99 \mathrm{~m}} \mathrm{Tc}$ was coupled to the antibody incubated in TBS (Table 3 ).

In a second step, we employed a similar experimental setting in order to simulate compound stability in dog serum. We used undiluted sera of four canine mammary carcinoma patients (patients' characteristics in Supplementary Table 2) and monitored the amount of tracer at $37^{\circ} \mathrm{C}$ for up to 4 hours. Although we observed some patient-to-patient variations, no statistically significant differences were detectable within this time frame (Figure 3B). Notably, even after 4 hours, still all patient sera contained at least $55 \%$ of intact ${ }^{99 \mathrm{~m}} \mathrm{Tc}$ DTPA-can225IgG.

We experienced a strongly reduced to completely diminished binding to EGFR when the radio-compound was formulated in $0.9 \% \mathrm{NaCl}$ or $\mathrm{NaOAc}$ and stored in this formulation for several hours. Upon closer investigation, we found that these buffers were not capable of fully neutralizing the remaining $\mathrm{NH}_{4} \mathrm{OAc}$ buffer after the PD10 purification, resulting in a lower $\mathrm{pH}$ of 5.4-5.7. We assumed that this low $\mathrm{pH}$ may account for partial protein denaturation which negatively influences antibody binding. Consequently, an enzyme-linked immunosorbent assay (ELISA) was performed: EGFR was coated as a capture antigen, followed by incubation with the unmodified original can225IgG being pre-incubated in the respective buffers, or freshly diluted can $225 \mathrm{IgG}$ as normalization control.

The antibody was pre-incubated for 30' in the $\mathrm{NH}_{4} \mathrm{OAc}$ buffer used during the ${ }^{99 \mathrm{~m}} \mathrm{Tc}-$ labeling in order to simulate the conditions during radiolabeling. All other pre-incubations were carried out for $2.5 \mathrm{~h}$, which is the expected maximum duration of all in vitro experiments of this study.

We observed approximately a $10 \%$ drop of binding in the $\mathrm{NH}_{4} \mathrm{OAc}$ sample and a $20 \%$ decrease in the $0.9 \% \mathrm{NaCl}$ formulation (Figure 3C). TBS (pH 7.4) seemed to be superior regarding protein stability, though not significantly. Moreover, TBS never displayed insufficient neutralization following radiolabeling. Thus, we concluded that TBS is the most suitable formulation and performed all further experiments onwards using this buffer system.

\section{Autoradiography of dog mammary carcinoma tissue}

Autoradiography of canine mammary carcinoma tissue sections was performed in order to confirm binding of ${ }^{99 m} \mathrm{mc}-D T P A-c a n 225 \operatorname{IgG}$ to native canine EGFR in tissue. Immunohistological staining confirmed EGFR 
Table 3: Stability of ${ }^{99}$ Tc-DTPA-can225IgG in various buffer formulations

\begin{tabular}{lcccc}
\hline Time & TBS (pH 7.4) & $\mathbf{0 . 9} \% \mathbf{~ N a C l}$ & NaOAc (pH 6.0) & NaOAc (pH 7.0) \\
\hline $\mathbf{6 0} \boldsymbol{y}^{\prime}$ & $87.11 \% \pm 6.04$ & $85.97 \% \pm 4.01$ & $88.35 \% \pm 11.08$ & $91.38 \% \pm 12.24$ \\
$\mathbf{1 2 0}$ & $71.95 \% \pm 10.47$ & $78.97 \% \pm 3.83$ & $81.23 \% \pm 15.00$ & $86.69 \% \pm 13.70$ \\
\hline
\end{tabular}

Amount of intact ${ }^{99 m}$ Tc-DTPA-can225IgG in different buffer formulations 60 and 120 minutes after radiolabeling. Data depicted in $\%$, normalized to time point 0 .
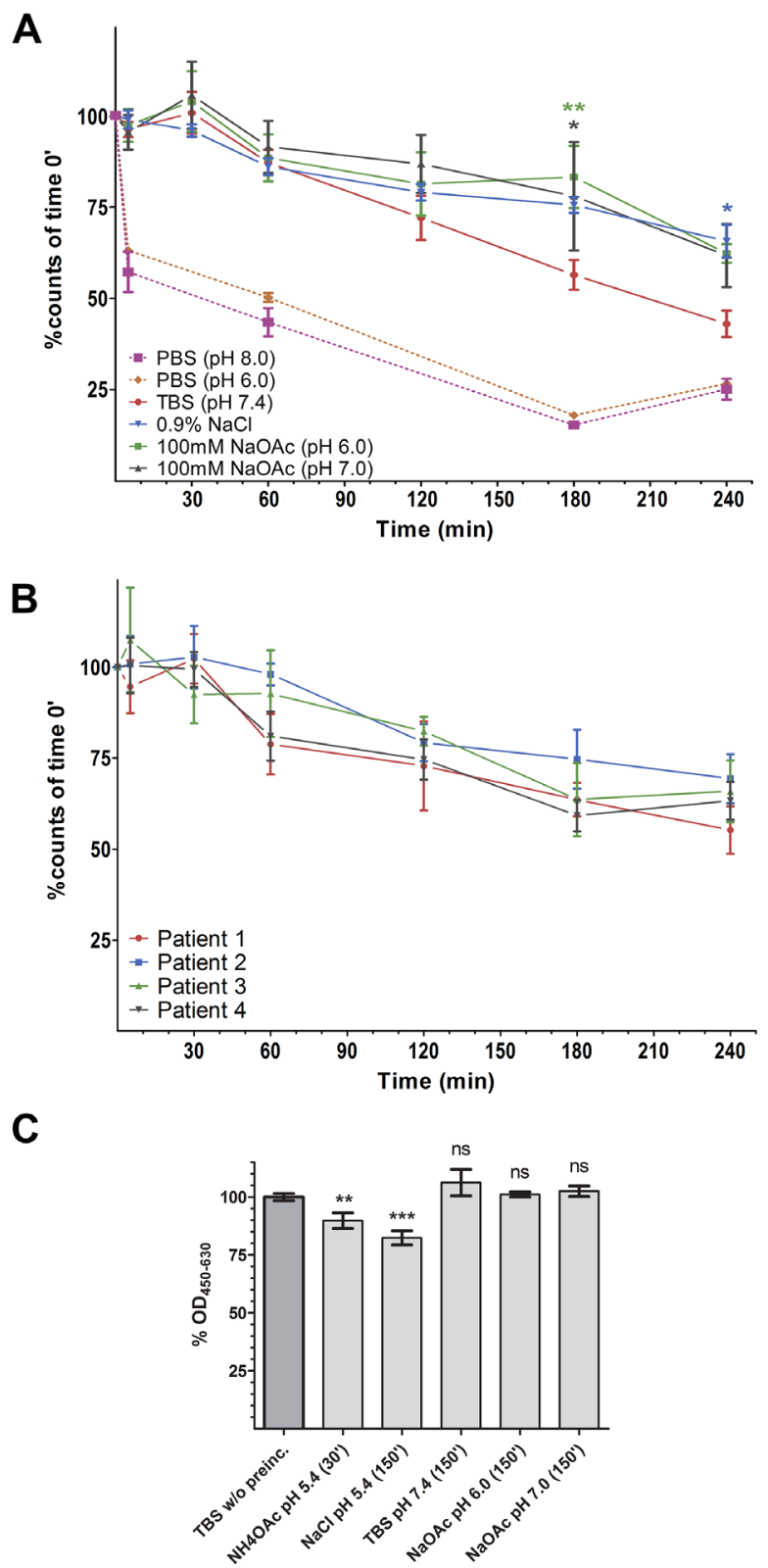

Figure 3: Radio- and protein-stability of ${ }^{99 \mathrm{~m}}$ Tc-DTPA-can225IgG. (A) $\%$ of intact ${ }^{99 \mathrm{~m}} \mathrm{Tc}-\mathrm{DTPA}$-can $225 \mathrm{IgG}$ in various buffers, normalized to time point 0 . Incubation was carried out at room temperature. Dotted pink line: PBS ( $\mathrm{pH} 8.0)(\mathrm{n}=2)$, Dotted orange line: PBS (pH 6.0) $(\mathrm{n}=2)$, Solid red line $-\mathrm{TBS}(\mathrm{pH} 7.4)$, blue $-0.9 \% \mathrm{NaCl}$, green $-\mathrm{NaOAc} \mathrm{pH} 6.0$, grey $-\mathrm{NaOAc} \mathrm{pH} 7.0$. Denoted significances refer to the buffer indicated by the color, compared to TBS; $n=3$. (B) $\%$ of intact ${ }^{99 \mathrm{~m} T c-D T P A-c a n} 225 \operatorname{IgG}$ in canine mammary carcinoma patient's sera, samples were incubated at $37^{\circ} \mathrm{C} ; \mathrm{n}=4$. (C) $\%$ Captured can $225 \operatorname{IgG}$ from of pre-incubated buffer samples, normalized to freshly prepared can225IgG. Statistical significances refer to differences in bound can225IgG compared to the reference sample; $n=3$. 
overexpression in all tested tissue samples in a membranespecific manner (Figure 4, second column; Supplementary Figures 1 and 2). The autoradiography of a subsequent section showed moderate to high uptake in the tissue. Here, activity was mainly concentrated at regions being highly positive for EGFR expression. (Figure 4 fourth and fifth column). The signal in row C, column 4 and 5 , appears blurry as it was recorded at the resolution limit of this technology. Patients' characteristics are disclosed in Supplementary Table 3.

\section{Real-time kinetics determination of ${ }^{99 \mathrm{~m}}$ Tc-DTPA- can225IgG}

In order to determine real-time kinetics and affinity of ${ }^{99 \mathrm{~m}}$ Tc-DTPA-can225IgG towards native canine EGFR, a competition binding assay using Ligand Tracer $\AA$ Yellow was performed and the uptake of the radioactive compound in Sh1b canine mammary carcinoma cells was measured. Using 3 different concentrations of the compound, we could determine $\mathrm{a}_{\mathrm{D}}$ of $0.8 \pm 0.0031$ $\mathrm{nM}$ towards naturally expressed canine EGFR (Figure $5)$. The respective dissociation rate constant $\mathrm{k}_{\mathrm{d}}$ has been determined as $4.93 \mathrm{e}^{-3} \pm 1.61 \mathrm{e}^{-5}$ and the association rate constant $\mathrm{k}_{\mathrm{a}}$ as $5.66 \mathrm{e}^{6} \pm 1.55 \mathrm{e}^{3}$.

\section{DISCUSSION}

Currently, decisions for patient stratification in clinical oncology heavily depend on histopathology. Especially for specific treatment of tumors with targeted therapies such as monoclonal antibodies, companion diagnostics evolved, determining the expression of a tumor-associated antigen (TAA) in the malignant tissue. Immunohistochemical in vitro diagnostic tests are available on the market for detection of EGFR overexpression, classifying tissues from EGFR negative to +++ positive [18].

While histopathology is most often obtained from a single biopsy site, and PET scans localize tumors throughout the body via their metabolic activity, information on the different EGFR expression levels on primary or secondary lesions could provide important information to the clinical oncologist and have direct implications on targeting strategies.

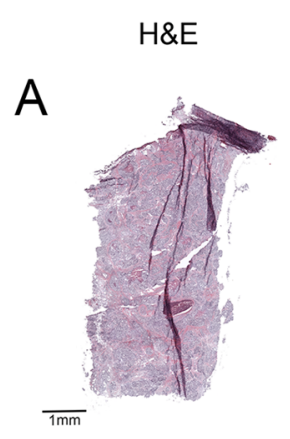

EGFR
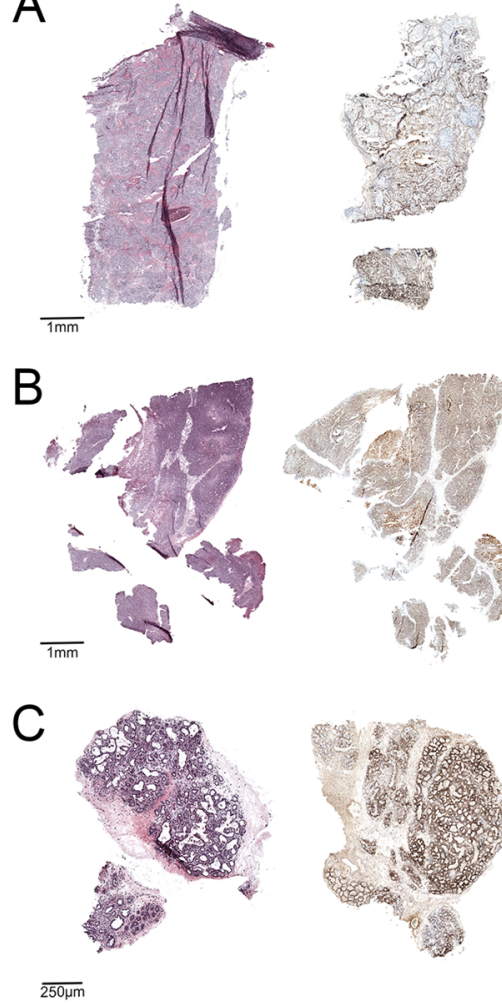

cresyl violet
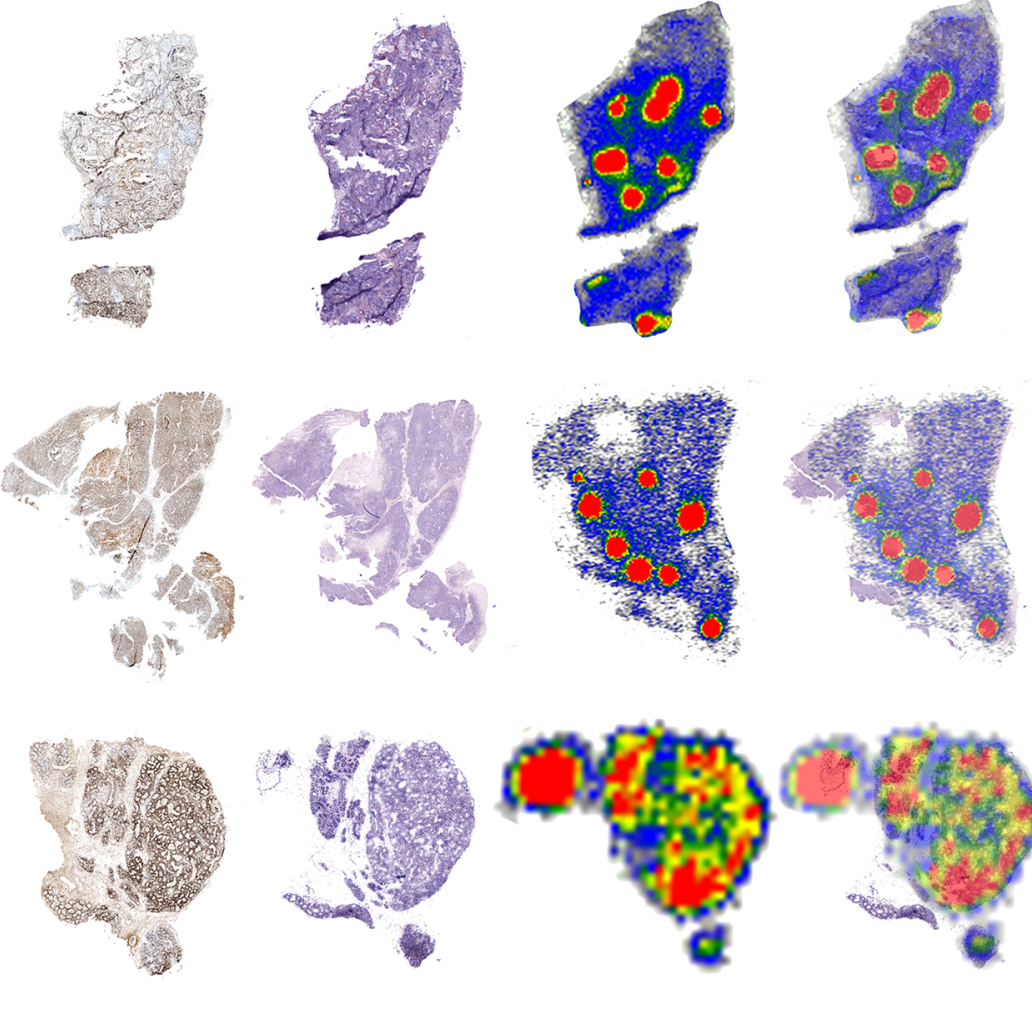

${ }^{99 m} T C-c a n 225 \lg G$

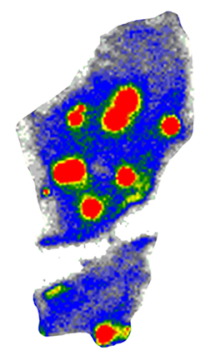

${ }^{99 \mathrm{~m} T c-c a n} 225 \mathrm{lgG}$
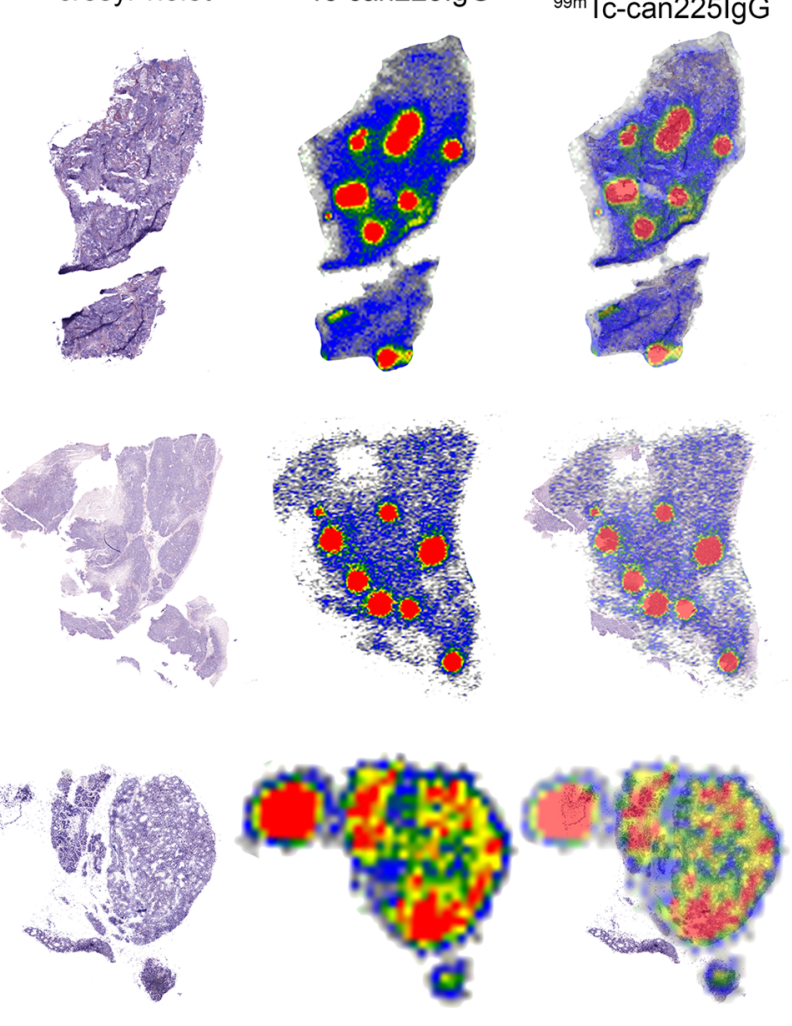

Figure 4: Immunohistochemistry and autoradiography of canine mammary carcinoma sections. $5 \mu \mathrm{m}$ tumor sections of 3 canine mammary carcinoma patients (A-C) were stained with hematoxylin/eosin (first column) and for EGFR expression (second column). $10 \mu \mathrm{m}$ sections of the same tumor were used for autoradiography with ${ }^{99 \mathrm{~m}} \mathrm{Tc}-\mathrm{DTPA}$-can225IgG (fourth column). The same sections used for autoradiography were stained with cresyl violet in order to visualize tissue morphology (third column) and were used to generate an overlay (fifth column). 
For management of neuroendocrine tumor patients, this strategy is already a cornerstone in clinical decisionfinding. As neuroendocrine tumors have relatively high expression levels of somatostatin-receptors (SSTRs) [19], several specific tracers were developed. The most commonly applied is the SSTR-ligand [ $\left.{ }^{111} \mathrm{In}-\mathrm{DTPA}^{0}\right]$ octreotide, which is used for diagnosis and staging. Tumors being positively marked by $\left[{ }^{111} \mathrm{In}_{-\mathrm{DTPA}}{ }^{0}\right]$ octreotide can be treated subsequently with SSTR-ligand bound therapeutic radionuclides, such as [ ${ }^{90} \mathrm{Y}$-DOTA0$\mathrm{Tyr}^{3}$ ]octreotide $\left({ }^{90} \mathrm{Y}\right.$-DOTATOC) and $\left[{ }^{177} \mathrm{Lu}\right.$-DOTA0-Tyr $\left.{ }^{3}\right]$ octreotate [20-22]. Such combinations of diagnosticallyand therapeutically-labeled molecules are often called "theranostic twins" [23].

The aim of this study was to establish a similar diagnostic option in a comparative medicine setting using can225IgG, a caninized version of the widely applied monoclonal antibody cetuximab. We could demonstrate that upon functionalization with DTPA, can225IgG can be effectively radiolabeled with ${ }^{99 \mathrm{~m}} \mathrm{Tc}$, a diagnostic SPECT-nuclide (Figures 1 and 2). Throughout all these modification steps, ${ }^{99 \mathrm{~m}} \mathrm{Tc}-\mathrm{DTPA}$-can $225 \mathrm{IgG}$ retained its specificity towards EGFR in solid phase (Figure 2E-2F), on the surface of cancer cells in solution (Figure 2B-2D) as well as in canine mammary carcinoma tissue (Figure 4). Furthermore, we could determine the affinity of ${ }^{99 m}$ Tc-DTPA-can225IgG in real-time competition binding assays using the LigandTracer ${ }$ Yellow. The obtained $\mathrm{K}_{\mathrm{D}}$ value of $0.8 \mathrm{nM}$ corresponds to a high-affinity binding typical of therapeutic monoclonal antibodies. Cetuximab, the human-mouse chimeric antibody that served as a template for can225IgG, has a $\mathrm{K}_{\mathrm{D}}$ value of $0.147 \mathrm{nM}$ towards EGFR expressed on A431 cells and $0.2 \mathrm{nM}$ determined using recombinant soluble EGFR [14]. Considering that the cetuximab binding epitope of canine EGFR differs in 4 amino acids [13] and the possible modifications through the functionalization procedure, the $K_{D}$ value we observed for ${ }^{99 m}$ Tc-DTPA-can225IgG is astonishingly good. The high affinity of ${ }^{99 \mathrm{~m}}$ Tc-DTPAcan225IgG to canine EGFR confirmed that the lower signal intensity observed in blots (Figure 2E) is most probably not a result of lower affinity of the antibody, but rather accountable to the difficulties encountered during the production of canine EGFR and its low stability. Nevertheless, these results do not provide any information about the in vivo kinetics of ${ }^{99 \mathrm{~m}} \mathrm{Tc}-\mathrm{DTPA}-$ can225IgG; the rate of tissue penetration and the uptake in tumors will have to be experimentally determined in the course of a clinical trial in canine carcinoma patients.

Considering direct anti-tumor effects of the antibody via growth signal inhibition or immune cell activation, we do not expect direct targeting effects due to the extremely low in vivo concentration of this tracer immunoglobulin. Typically, the dosages of radioactive antibody tracers (for diagnostic purposes) range between 0.1-0.4 GBq [24], which would be approximately 10$30 \mu \mathrm{g}$ can $225 \operatorname{IgG}$, considering the specific activity we achieved in this study. For an average canine patient of $20 \mathrm{~kg}\left(0.744 \mathrm{~m}^{2}\right.$ body surface area [25]) as an example, the dosage roughly equals $0.04 \mathrm{mg} / \mathrm{m}^{2}$. On the contrary, the approved therapeutic dose of cetuximab for human patients is $400 \mathrm{mg} / \mathrm{m}^{2}$ as an initial dose, followed by 250 $\mathrm{mg} / \mathrm{m}^{2}$ as weekly maintenance dose [26]. Presumably, using an up to 10.000-fold lower antibody concentration than the current clinically applied doses would not show any signal inhibition or immunological effect in an in vivo model or in a clinical study with canine patients.

We could demonstrate that ${ }^{99 \mathrm{~m}}$ Tc-DTPA-can $225 \mathrm{IgG}$ is stable in four different buffers (Figure 3A), all of which are suitable for intravenous injection. As radiolabeling facilities and SPECT-cameras can be in different locations, it was crucial to prove the stability of ${ }^{99 \mathrm{~m}} \mathrm{Tc}-\mathrm{DTPA}-$

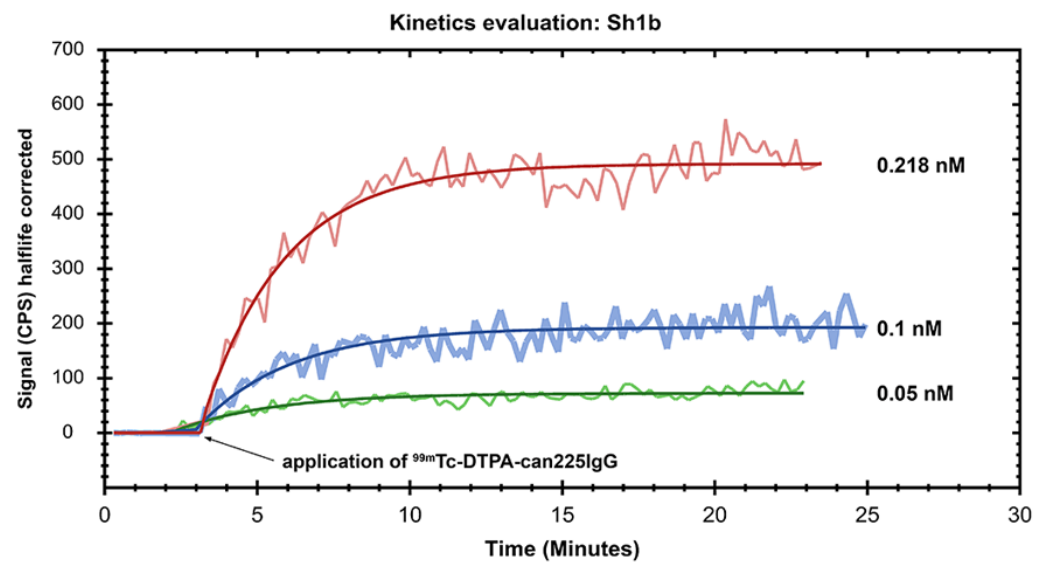

Figure 5: Affinity determination of ${ }^{99 m}$ Tc-DTPA-can225IgG towards canine EGFR. The EGFR+ canine mammary carcinoma cell line Sh1b was used to determine the affinity of ${ }^{99 m}$ Tc-DTPA-can225IgG in a Ligand Tracer ${ }^{\circledR}$ approach. Real-time association was measured by incubation of the cells with $0.05 \mathrm{nM}$ (green line), $0.1 \mathrm{nM}$ (blue line) and $0.218 \mathrm{nM}$ (red line) ${ }^{99 m}$ Tc-DTPA-can225IgG until equilibrium was reached. Binding kinetics were calculated using a 1 to 1 ligand-target fitting algorithm. 
can225IgG for transportation and short term storage at room temperature. Our results indicate that under neutral $\mathrm{pH}$ the reagent can be stored for up to $1 \mathrm{~h}$, which should be suitable for transportation as well as patient preparation.

Another important point was to determine whether ${ }^{99 m}$ Tc-DTPA-can225IgG would be also stable in serum following intravenous administration. Here we could demonstrate stability with non-significant patient-to-patient variability for up to four hours, although these serum samples were derived from four different dog breeds.

Furthermore, after 4 hours, more than $55 \%$ of ${ }^{99 \mathrm{~m}} \mathrm{Tc}-$ DTPA-can225IgG was still intact in all tested serum samples. A study by Ping et al. [27] demonstrated in a mouse model, that $20 \mathrm{~h}$ after administration uptake of ${ }^{64} \mathrm{Cu}-\mathrm{DOTA}$ cetuximab in EGFR-positive tumor tissue was visible in PET. Although the in vitro stability of ${ }^{99}$ Tc-DTPA-can $225 \mathrm{IgG}$ suggests trans-chelation to serum proteins, a positive performance for imaging is not discarded yet. A previous report [28] evidenced successful PET imaging of HER2 in a mouse model of ovarian carcinoma, despite the poor stability in serum of the ${ }^{89} \mathrm{Zr}$-labeled antibody utilized. We thus assume that ${ }^{99 \mathrm{~m}}$ Tc-DTPA-can225IgG may be stable enough for in vivo imaging; however the optimal time point to scan the patient has still to be determined in clinical trials. Therefore, we propose ${ }^{99 \mathrm{~m}}$ Tc-DTPA-can $225 \mathrm{IgG}$ a valuable tool to introduce TAA-specific whole body imaging in veterinary oncology.

Based on the outcome of these future scans, one would not only be able to precisely localize EGFR+ tumors in the individual patients, but also collect valuable information on the pharmacokinetics of tumortargeting monoclonal canine IgGs for the first time. This could further advance the development of specific EGFR-targeting antibodies, such as can225IgG, for dog tumor patients. As this antibody could also be labeled with therapeutic radionuclides, e.g. Yttrium-90 $\left({ }^{90} \mathrm{Y}\right)$ or Lutetium-177 $\left({ }^{177} \mathrm{Lu}\right)$ "theranostic twins" could also be developed leading to highly specific as well as effective anti-cancer therapies.

Simultaneously, these clinical trials with dog patients suffering from spontaneously occurring tumors would provide insights for a possible translation of this approach back to human oncology, or to other species, like cats, that are also heavily affected by EGFRoverexpressing malignancies [29]. Also here, this novel theranostic approach could exploit imaging options in order to select patients more effectively.

\section{MATERIALS AND METHODS}

\section{Cell lines, can225IgG and antigens}

The human EGFR-overexpressing epithelial carcinoma cell line A431 (ATCC $®$ CRL-1555 ${ }^{\mathrm{TM}}$ ), the human embryonic kidney cell line 293T (ATCC®) CRL3216 ${ }^{\mathrm{TM}}$ ) and the chinese hamster ovary cell line CHO-K1 (ATCC ${ }^{\circledR}$ CCL-61 ${ }^{\mathrm{TM}}$ ) were obtained from the
American Type Culture Collection (ATCC, Manassas, VA, USA). The canine mammary carcinoma cell line Sh1b was kindly provided by Prof. Dr. Gerard Rutteman from the Department of Clinic Science and Companion Animals, University of Utrecht, Utrecht, the Netherlands. A431 and HEK293T were cultured in Dulbecco`s Modified Eagle Medium (cat\# 11995065, Gibco), supplemented with 10\% fetal bovine serum (cat\# 10270106, Gibco), 2 mM Glutamine (cat\# 25030081, Gibco), $100 \mathrm{U} / \mathrm{ml}$ Penicillin and $100 \mu \mathrm{g} / \mathrm{ml}$ Streptomycin (cat\# 15140122, Gibco); CHO-K1 was grown in Ham's F-12 Nutrient Mix (cat\# 21765029, Gibco) supplemented with 10\% fetal bovine serum (cat\# 10270106, Gibco), $100 \mathrm{U} / \mathrm{ml}$ Penicillin and $100 \mu \mathrm{g} / \mathrm{ml}$ Streptomycin (cat\# 15140122, Gibco) and Sh1b was cultured in Ham's F-12 Nutrient Mix (cat\# 21765029, Gibco) supplemented with $10 \%$ fetal bovine serum (cat\# 10270106, Gibco) and 10 $\mu \mathrm{g} / \mathrm{ml}$ gentamycin sulphate (cat\# 2475.1, Carl Roth). The cells were grown at passages $5-17$ at $37^{\circ} \mathrm{C}$ under a humidified atmosphere with $5 \% \mathrm{CO}_{2}$. 293T has been freshly purchased from ATCC and the identity of A431 has been authenticated by Multiplexion (Heidelberg, Germany) prior to experiments.

Can225IgG was produced in CHO DUKX-B11 cells as described by Singer, Fazekas et al. [16].

Recombinant soluble human EGFR was purchased from ACROBiosystems (cat\# EGR-H5222).

Recombinant soluble canine EGFR was produced in HEK293T cells. Detailed information about the expression and the sequence is disclosed in the Supplementary Materials and Supplementary Table 1.

Recombinant soluble human HER-2 was produced by Lec-1 cells [30], which were kindly provided by Prof. Daniel Leahy from Johns Hopkins University School of Medicine (Baltimore, Maryland, USA).

\section{Structural modeling of can225IgG}

Modeling of can225IgG was done by using MODELLER version9v8, as described in Singer, Fazekas et al. [16]. p-SCN-Bn-DTPA was modeled by ChemDraw release 16.0 (Perkin Elmer, Waltham, MA, USA).

\section{Functionalization of can225IgG with DTPA}

Can225IgG was functionalized for subsequent radiolabeling with S-2-(4-isothiocyanatobenzyl)diethylene-triamine-pentaacetic acid (p-SCN-Bn-DTPA, in following 'DTPA') at piCHEM (Graz, Austria). For this reaction, DTPA was dissolved in DMSO at a concentration of $10 \mathrm{mg} / \mathrm{ml}$. Can225IgG $(2 \mathrm{mg} / \mathrm{ml}$, dissolved in 0.1 M PBS, $\mathrm{pH}$ 8.0) was mixed with DTPA at a molar excess defined below (E1-3). The reaction mix was then allowed to react at room temperature for $2 \mathrm{~h}$ and then gently shaken at $4^{\circ} \mathrm{C}$ over night. The next day, the reaction mix was diluted with PBS pH 7.2 and excess of the chelator was removed by G25 Sephadex 
size exclusion purification (PD-10 column, cat\# 170851-01, GE Healthcare). Fractions containing the DTPA labeled antibody were eluted with $0.1 \mathrm{M}$ PBS pH 7.2 and collected. In order to optimize the functionalization of the antibody for subsequent experiments, we tested 3 different experimental conditions (can225IgG E1-E3): can225IgG E1 was generated by using a 25:1 molar excess of DTPA to can225IgG; can225IgG E2 was functionalized with 50x molar excess of DTPA and finally, can225IgG E3 was also functionalized with a 50:1 molar ratio of DTPA to antibody, however, the reaction was carried out at a $\mathrm{pH}$ of 9.0 instead of 8.0.

\section{Radiolabeling of the DTPA-functionalized can225IgG with ${ }^{99 m}$ Tc}

${ }^{99} \mathrm{TcO}_{4}{ }^{-}$was eluted from a ${ }^{99} \mathrm{Mo} /{ }^{99 m} \mathrm{Tc}$ generator with sterile $0.9 \% \mathrm{NaCl} .200 \mu \mathrm{L}$ of the eluate (typically with an activity of $\sim 1 \mathrm{GBq}$ ) was added to the reaction vessel, containing $400 \mu 100 \mathrm{mM} \mathrm{NH}_{4} \mathrm{OAc}(\mathrm{pH}$ 5.4), 50 $\mu \mathrm{g}$ DTPA-can225IgG and $3 \mu \mathrm{L}$ of a reduction solution (2.4 $\mathrm{mM} \mathrm{SnCl}_{2}$ (cat\# 818150, Merck) and $4.25 \mathrm{mM}$ L-ascorbic acid (cat\# A5960, Sigma-Aldrich) in sterile $0.9 \% \mathrm{NaCl}$ previously purged with argon). The reaction mixture was stirred for $25 \mathrm{~min}$ at room temperature (RT). The crude product was then purified with a Sephadex ${ }^{\mathrm{TM}}$ G25M PD-10 column (cat\# 17-0851-01, GE Healthcare) and fraction-wise eluted with TBS ( $\mathrm{pH}$ 7.4). Purity of the radiolabeled antibody was assessed via instant thin layer chromatography, using glass microfiber chromatography paper impregnated with silica-gel (iTLC-SG) (cat\# SGI0001, Agilent Technologies, Santa Clara, CA, USA) and $0.9 \% \mathrm{NaCl}$ as mobile phase. In order to obtain the precise specific activity for each radiolabeling batch, protein concentration of the final product was determined according to the microassay protocol of the Quick Start ${ }^{\mathrm{TM}}$ Bradford Protein Assay (cat\# 5000201, Bio-Rad Laboratories) using purified canine IgG (cat\# IR-DG-GF, Dunn Labortechnik) for the standard curve.

\section{PAGE and immunoblots}

All gels and blots were performed using $4-15 \%$ Mini-PROTEAN® TGX ${ }^{\mathrm{TM}}$ precast gels (cat\# 4561084, Bio-Rad Laboratories), at running conditions of $200 \mathrm{~V}$ for 32 minutes in standard PAGE buffer by Laemmli. Molecular weight markers used: PageRuler Plus prestained protein ladder, 10-250 kDa (cat\# 26612, ThermoFisher) and Spectra ${ }^{\mathrm{TM}}$ Multicolor high range protein ladder, 40$300 \mathrm{kDa}$ (cat\# 26625, ThermoFisher, lot\# 00316364). Gels for the molecular weight analysis were stained with SimplyBlue ${ }^{\text {TM }}$ SafeStain (cat\# LC6060, Life Technologies) according to the manufacturer's instructions.

For western and radio-blots, proteins were blotted onto $0.2 \mu \mathrm{m}$ pore-sized nitrocellulose membranes (cat\# 10600001, GE Healthcare) using a semi-dry blotting device (Bio-Rad Laboratories) at a current of $80 \mathrm{~mA} / \mathrm{gel}$ for 60 minutes. Subsequently, membranes were blocked by $5 \%$ skimmed milk powder solubilized in TBST (50 $\mathrm{mM}$ TRIS, $150 \mathrm{mM} \mathrm{NaCl}, 0.1 \%$ Tween-20, $\mathrm{pH}$ 7.4) for $60 \mathrm{~min}$ at RT.

To verify antibody integrity, unmodified and DTPAconjugated can225IgG was detected by HRP-labeled anti-dog $\operatorname{IgG}(\mathrm{Fc})$ antibody (cat\# 304-035-008, Jackson ImmunoResearch Europe), diluted 1:5000 in blocking buffer and incubated for 60 minutes at RT. Following washing with TBST $(3 \times 10$ minutes $)$, membranes were developed with an ECL substrate (cat \# RPN2232, GE Healthcare) using a CCD-based VersaDoc Imaging System (Bio-Rad Laboratories, Hercules, CA, USA).

Soluble human EGFR was detected stripe-wise by unmodified can225IgG and by can225IgG-DTPA E1E3 at concentrations of $1 \mu \mathrm{g} / \mathrm{ml}$ in blocking buffer and incubated for $60 \mathrm{~min}$ at RT. Upon washing with TBST, the membrane was incubated with HRP-labeled anti-dog $\operatorname{IgG}(\mathrm{Fc})$ antibody (1:5000, diluted in blocking buffer) for $60 \mathrm{~min}$ at RT. After a final washing step, the membrane was developed as described above.

Radioblots were incubated with approximately 100-200 kBq ${ }^{99 \mathrm{~m}}$ Tc-DTPA-can225IgG diluted in blocking buffer for $1 \mathrm{~h}$ at RT. The pre-blocked radioblot (see Supp. Figure 3 for detailed assay scheme) was additionally pre-incubated with $10 \mu \mathrm{g} / \mathrm{ml}$ unlabeled can $225 \mathrm{IgG}$ prior to incubation with the radiolabeled antibody. Following incubation with the radiolabeled compound, blots were washed 3 times 5' with TBST and imaged using an Instant Imager v1.27 (Packard Instruments Company, Meriden, CT, USA).

\section{Mass spectroscopy}

Mass spectroscopy analysis was carried out on a Bruker Microflex MALDI-TOF device using the software 'flexControl' v2.4 (Bruker, Billerica, MA, USA). Antibody solutions $(\sim 0.2 \mu \mathrm{g} / \mathrm{ml})$ were dotted on a sinapinic acid matrix (cat\# 8201345, Bruker) and ionized at 81\% laser power. Mass spectra were converted to mzML using MSConvertGUI (ProteoWizard) and analyzed using mMass v5.5.0 (@) Martin Strohalm). Baseline correction parameters: Precision 15, Relative offset 25. Smoothing window size: $40 \%$ of main peak width at $50 \%$ intensity, can225IgG light chain: 32 , heavy chain: 404 , can225IgGDTPA light chain: 350, heavy chain: 637.

\section{Flow cytometry}

$3 \times 10^{5}$ cells were stained with $10 \mu \mathrm{g} / \mathrm{ml} \mu \mathrm{g}$ of either unmodified can225IgG or one variant of the functionalized can225IgG E1-E3 or isotype antibody (canine IgG standard, cat\# IR-DG-GF, Dunn Labortechnik) in PBS+2\% normal goat serum (NGS) for $30 \mathrm{~min}$ on ice. Following a washing step with $\mathrm{PBS}+2 \%$ NGS, bound $\operatorname{dog}$ IgG was detected 
with $10 \mu \mathrm{g} / \mathrm{ml}$ FITC-labeled anti dog IgG (cat\# 304-095008, Jackson Immuno Research), incubated for $30 \mathrm{~min}$ on ice and followed by 2 washing steps with PBS+2\% NGS. Subsequently, 10.000 single/viable cells were recorded on a FACSCalibur ${ }^{\mathrm{TM}}$ (BD Biosciences, Franklin Lakes, NJ, USA). Data analysis was performed using FlowJo v10.0.7 software (Flow Jo LLC, Ashland, OR, USA).

\section{Serum/buffer stability; instant thin-layer chromatography}

In order to determine the amount of intact tracer over time and to find an ideal formulation for a small intravenous bolus application, ${ }^{99 \mathrm{~m}}$ Tc-DTPA-can225IgG was incubated in various buffers and in dog serum. Sera were obtained in the course of diagnostic workups at the Oncology Unit at the Small Animal Hospital, University of Veterinary Medicine Vienna (Vienna, Austria). Buffer mixtures were then incubated at room temperature and sera at $37^{\circ} \mathrm{C}$ in order to simulate storage and transport conditions or in vivo stability. Stability was monitored for 4 hours altogether. At specific time points, $2 \mu \mathrm{l}$ aliquots of the incubation mixtures were analyzed by instant thin layer radio-chromatography using $0.9 \% \mathrm{NaCl}$ as mobile phase. Subsequently, dry chromatography sheets were read out using the Instant Imager v 1.27 (Packard Instruments Company, Meriden, CT, USA) and processed with 'Imager' software, version 2.05 for Windows 95 (Packard Instruments Company, Meriden, CT, USA). The amount of intact tracer was determined as the percentage of total radioactivity bound to the silica gel paper $\left(\mathrm{R}_{\mathrm{f}}=0\right)$, whereas the amount of ${ }^{99} \mathrm{TcO}_{4}-$ was determined using the radioactivity moved with the solvent front $\left(\mathrm{R}_{\mathrm{f}}=1\right)$. Stability of the compound was normalized to the amount of intact tracer measured at time point 0 . All stability tests were performed in quadruplicates.

\section{Enzyme-linked immunosorbent assay (ELISA)}

96-well Maxisorp Nunc-immunoplates (cat\# 442404, ThermoFisher) were coated over night with 1 $\mu \mathrm{g} / \mathrm{ml}$ human soluble EGFR. Following blocking with the TBS-based SuperBlock blocking buffer (cat\# 37535, ThermoFisher), $1 \mu \mathrm{g} / \mathrm{ml}$ solutions of can225IgG were applied to the plate in triplicates (samples: freshly diluted can $225 \mathrm{IgG}$ in TBS, $30 \mathrm{~min}$ pre-incubated can $225 \mathrm{IgG}$ in NH4OAc, $150 \mathrm{~min}$ pre-incubated can225IgG in $0.9 \% \mathrm{NaCl}(\mathrm{pH} 5.4)$, TBS ( $\mathrm{pH} 7.4), 100 \mathrm{mM} \mathrm{NaOAc}$ (pH 6.0) and $100 \mathrm{mM} \mathrm{NaOAc}(\mathrm{pH}$ 7.0)). Following $1 \mathrm{~h}$ incubation, bound can225IgG was detected by a HRPlabeled anti-dog $\operatorname{IgG}(\mathrm{Fc})$ antibody (cat\# 304-035-008, Jackson ImmunoResearch Europe), 1:5000 diluted in TBS $+0.05 \%$ Tween- $20+2 \%$ BSA. Bound detection antibody was visualized by TMB OptEia substrate (cat\# 555214, BD Biosciences) and recorded at $450 \mathrm{~nm}$ (and $630 \mathrm{~nm}$ reference wavelength) using the Infinite ${ }^{\circledR}$ M200 microplate reader (Tecan, Männedorf, Switzerland).

\section{Immunohistochemistry}

Canine mammary carcinoma tissue samples were purchased from the VetBioBank of the VetCore, Veterinary University of Vienna. For the immunohistochemical and H\&E stainings, $5 \mu \mathrm{m}$ thick sections of frozen canine mammary carcinoma samples were fixed with ice cold acetone for 10 minutes, then after air drying, washed in PBS for another 10 minutes. H\&E staining was performed according to standard protocols. Slides for EGFR were fixed in 10\% neutral buffered formaldehyde for $10 \mathrm{~min}$ and then stained with the DAKO EGFR PharmDX ${ }^{\mathrm{TM}}$ kit (Agilent Technologies) including isotype controls, according to the manufacturer's instructions. Stained slides were subsequently mounted with Fluoromount (cat\# F4680, Sigma-Aldrich) and recorded with the Tissue FAXS automated scanning system (TissueGnostics, Vienna, Austria) at 20x magnification.

\section{Autoradiography}

$10 \mu \mathrm{m}$ thick, untreated frozen canine mammary carcinoma sections were thawn for 5 minutes at RT and then blocked in TBS $+2 \%$ bovine serum albumin (BSA) for $30 \mathrm{~min}$. The slides were then incubated with $\sim 30 \mathrm{kBq} /$ section ${ }^{99 \mathrm{~m}} \mathrm{Tc}-\mathrm{DTPA}-\mathrm{can} 225 \mathrm{IgG}$ for $1 \mathrm{~h}$ at RT. Subsequently, slides were incubated $2 \mathrm{x}$ for $5 \mathrm{~min}$ in icecold $\mathrm{TBS}+2 \%$ BSA and then dipped 10x into ice-cold $\mathrm{H} 2 \mathrm{O}$ followed by drying under a cold air stream. Dry slides were placed on multisensitive phosphor screens (cat\# 7001724, Perkin Elmer) for 24h and then recorded in a Cyclone Plus phosphor imager and analyzed using the OptiQuant ${ }^{\circledR}$ software (Perkin Elmer).

\section{Cresyl violet staining}

The same slides used for autoradiography (5-6 half times post staining) were fixed in PBS $+10 \%$ formaldehyde for $10 \mathrm{~min}$ and then rinsed briefly in $\mathrm{H}_{2} \mathrm{O}$. Slides were then stained for $30 \mathrm{~min}$ in a bath of cresyl violet staining solution ( $1 \% \mathrm{w} / \mathrm{v}$ cresyl violet (cat\# C504, Sigma-Aldrich) and $1 \%$ glacial acetic acid in $\mathrm{H}_{2} \mathrm{O}$ ) at $60^{\circ} \mathrm{C}$. Following a brief rinse in $\mathrm{H}_{2} \mathrm{O}$, slides were differentiated in subsequent baths of $70 \% \mathrm{EtOH}$ and $95 \% \mathrm{EtOH}$ followed by a quick dip into $100 \%$ EtOH. Slides were then cleared by 2 subsequent washes with xylene and mounted with Histofluid (cat\# 6900002, Marienfeld Superior). All slides were then recorded with the Tissue FAXS automated scanning system at 20x magnification.

\section{Affinity determination using Ligand Tracer ${ }^{\circledR}$ Yellow}

The canine mammary carcinoma cell line Sh1b was seeded at $1 \times 10^{6}$ cells $/ \mathrm{ml}(2.5 \mathrm{ml}$ total volume $)$ in $100 \mathrm{~mm} * 20$ $\mathrm{mm}$ tissue culture dishes (cat\# 664160, Greiner Bio-One) and incubated overnight in a tilted position in order to facilitate cell 
growth at one side of the dish only. The next day, cell culture medium was changed and the dish was moved to horizontal position for 24 hours for the purpose of blocking free binding sites on the plastic dish by the fetal bovine serum found in the media. For real-time kinetics assessment, the Ligand Tracer ${ }^{\circledR}$ Yellow (Ridgeview Instruments, Uppsala, Sweden) was employed: after background measurement, we applied $2.5 \mathrm{ml}$ DMEM with $0.05 \mathrm{nM}, 0.1 \mathrm{nM}$ or $0.218 \mathrm{nM}{ }^{99 \mathrm{~m}} \mathrm{Tc}-$ DTPA-can225IgG and measured radioactivity at the cellcovered and the cell-free pole of the dish for 3 seconds, with 2 seconds waiting time in between. The background-corrected signal was then employed to calculate the kinetics using the TraceDrawer software v 1.7.1 (Ridgeview Instruments, Uppsala, Sweden) using the 1:1 ligand-target model.

\section{Statistical testing}

All statistical analyses were carried out using GraphPad Prism v5.00 for Windows. We employed two-way ANOVA with Bonferroni's post-test (CI: 95\%) to determine statistical significances in the stability-testing (Figure 3A-3B) and one-way ANOVA combined with Bonferroni's post-test (CI: 95\%) in order to compare experimental settings in regard of protein stability (Figure 3C). Statistical significance is defined as $*(\mathrm{p}<0.05) ; * *(\mathrm{p}<0.01)$ and $* * *(\mathrm{p}<0.001)$.

\section{Abbreviations}

\begin{tabular}{|c|c|}
\hline $\mathrm{ADCC}$ & $\begin{array}{l}\text { antibody-dependent cellular } \\
\text { cytotoxicity }\end{array}$ \\
\hline ADCP & $\begin{array}{l}\text { antibody-dependent cellular } \\
\text { phagocytosis }\end{array}$ \\
\hline$\left[{ }^{18} \mathrm{~F}\right] \mathrm{FDG}$ & 2-deoxy-2-[ $\left[{ }^{18} \mathrm{~F}\right]$ fluoro-D-glucose \\
\hline${ }^{99 \mathrm{~m}} \mathrm{Tc}$ & technetium-99m \\
\hline BSA & bovine serum albumin \\
\hline $\mathrm{CT}$ & computed tomography \\
\hline DTPA & diethylene-triamine-pentaacetic acid \\
\hline E1-3 & $\begin{array}{l}\text { experimental setting 1-3 (of } \\
\text { functionalization) }\end{array}$ \\
\hline EGFR & epidermal growth factor receptor-1 \\
\hline ELISA & enzyme-linked immunosorbent assay \\
\hline HER-2 & $\begin{array}{l}\text { human epidermal growth factor } \\
\text { receptor } 2\end{array}$ \\
\hline ITLC & instant thin layer chromatography \\
\hline $\mathrm{k}_{\mathrm{a}}$ & association rate constant \\
\hline $\mathrm{K}_{\mathrm{D}}$ & equilibrium dissociation constant \\
\hline $\mathrm{k}_{\mathrm{d}}$ & dissociation rate constant \\
\hline MALDI-TOF & $\begin{array}{l}\text { matrix-assisted laser desorption } \\
\text { ionization - time of flight }\end{array}$ \\
\hline
\end{tabular}

\begin{tabular}{ll} 
NGS & normal goat serum \\
PAGE & polyacrylamide gel electrophoresis \\
PET & positron emission tomography \\
SPECT & $\begin{array}{l}\text { single-photon emission computed } \\
\text { tomography }\end{array}$ \\
SSTR & somatostatin-receptor \\
TAA & tumor-associated antigen \\
\hline
\end{tabular}

\section{Author contributions}

Conception and design of the study: JFS, NBI, CRM, MD, MW, FA, JS, WW, M. Mitterhauser and EJJ. Data collection: JFS, NBI, CRM, MD and M. Matz. Data analysis and interpretation: JFS, NBI and CRM. Drafting the manuscript: JFS, NBI and CRM. Preparation of figures: JFS. Critical revision of the manuscript: FA, JS, WW, M. Mitterhauser and EJJ. Final approval of the manuscript: JFS, NBI, CRM, MD, M. Matz, MW, FA, JS, WW, M. Mitterhauser and EJJ.

\section{ACKNOWLEDGMENTS}

The authors would like to thank Prof. Margit FockeTejkl for kind help with the mass spectrometry, Markus Zeilinger and Florian Pichler for their kind support with the kinetics experiments and Prof. Ingrid Walter and Stefan Kummer from the VetBioBank of the VetCore, Veterinary University of Vienna for providing the tissue slides. We are grateful to Prof. Thomas Stockner for support in graphical visualization of the antibody. Moreover, we would like to thank Theresa Balber, Sarah Pfaff and Chrysoula Vraka for fruitful discussions and their technical advice throughout the project.

\section{CONFLICTS OF INTEREST}

The authors declare that there is no conflicts of interest with regard to this publication.

\section{FUNDING}

This work was supported by the Austrian Science Fund (FWF) grants P23398-B11 and W1205-B09.

\section{REFERENCES}

1. Mankoff DA, Specht JM, Eubank WB, Kessler L. [(18) F]fluorodeoxyglucose positron emission tomographycomputed tomography in breast cancer: when... and when not? J Clin Oncol. 2012; 30:1252-1254.

2. Fukuda H, Kubota K, Matsuzawa T. Pioneering and fundamental achievements on the development of positron 
emission tomography (PET) in oncology. Tohoku J Exp Med. 2013; 230:155-169.

3. Adejolu M, Huo L, Rohren E, Santiago L, Yang WT. Falsepositive lesions mimicking breast cancer on FDG PET and PET/CT. AJR Am J Roentgenol. 2012; 198:W304-W314.

4. Tagliabue L, Del Sole A. Appropriate use of positron emission tomography with [(18)F]fluorodeoxyglucose for staging of oncology patients. Eur J Intern Med. 2014; 25:6-11.

5. Yewale C, Baradia D, Vhora I, Patil S, Misra A. Epidermal growth factor receptor targeting in cancer: a review of trends and strategies. Biomaterials. 2013; 34:8690-8707.

6. Fleuren ED, Versleijen-Jonkers YM, Heskamp S, van Herpen CM, Oyen WJ, van der Graaf WT, Boerman OC. Theranostic applications of antibodies in oncology. Mol Oncol. 2014; 8:799-812.

7. Simon R. Lost in translation: problems and pitfalls in translating laboratory observations to clinical utility. Eur J Cancer. 2008; 44:2707-2713.

8. Gordon I, Paoloni M, Mazcko C, Khanna C. The Comparative Oncology Trials Consortium: using spontaneously occurring cancers in dogs to inform the cancer drug development pathway. PLoS Med. 2009; 6:e1000161

9. Furdos I, Fazekas J, Singer J, Jensen-Jarolim E. Translating clinical trials from human to veterinary oncology and back. J Transl Med. 2015; 13:265.

10. Singer J, Jensen-Jarolim E. IgE-based immunotherapy of cancer -a comparative oncology approach. J Carcinog Mutagen. 2014; 5:1000176.

11. Iezzi M, Quaglino E, Amici A, Lollini PL, Forni G, Cavallo F. DNA vaccination against oncoantigens: a promise. Oncoimmunology. 2012; 1:316-325.

12. Weichselbaumer M, Willmann M, Reifinger M, Singer J, Bajna E, Sobanov Y, Mechtcherikova D, Selzer E, Thalhammer JG, Kammerer R, Jensen-Jarolim E. Phylogenetic discordance of human and canine carcinoembryonic antigen (CEA, CEACAM) families, but striking identity of the CEA receptors will impact comparative oncology studies. PLoS Curr. 2011; 3:Rrn1223.

13. Singer J, Weichselbaumer M, Stockner T, Mechtcheriakova D, Sobanov Y, Bajna E, Wrba F, Horvat R, Thalhammer JG, Willmann M, Jensen-Jarolim E. Comparative oncology: ErbB-1 and ErbB-2 homologues in canine cancer are susceptible to cetuximab and trastuzumab targeting. Mol Immunol. 2012; 50:200-209.

14. Goldstein NI, Prewett M, Zuklys K, Rockwell P, Mendelsohn J. Biological efficacy of a chimeric antibody to the epidermal growth factor receptor in a human tumor xenograft model. Clin Cancer Res. 1995; 1:1311-1318.

15. Mendelsohn J. Epidermal growth factor receptor inhibition by a monoclonal antibody as anticancer therapy. Clin Cancer Res. 1997; 3:2703-2707.

16. Singer J, Fazekas J, Wang W, Weichselbaumer M, Matz M, Mader A, Steinfellner W, Meitz S, Mechtcheriakova
D, Sobanov Y, Willmann M, Stockner T, Spillner E, et al. Generation of a canine anti-EGFR (ErbB-1) antibody for passive immunotherapy in dog cancer patients. Mol Cancer Ther. 2014; 13:1777-1790.

17. (2016). ClinicalTrials.gov by The National Library of Medicine (US). (Bethesda (MD). Date of access: 01/12/2016 (2016).

18. (2006) Dako, Agilent Technologies. EGFR pharmDx Interpretation Manual. Date of access: 01/12/2016.

19. Gatto F, Hofland LJ. The role of somatostatin and dopamine D2 receptors in endocrine tumors. Endocr Relat Cancer. 2011; 18:R233-R251.

20. Xu C, Zhang $\mathrm{H}$. Somatostatin receptor based imaging and radionuclide therapy. Biomed Res Int. 2015; 2015:917968.

21. Theodoropoulou M, Stalla GK. Somatostatin receptors: from signaling to clinical practice. Front Neuroendocrinol. $2013 ; 34: 228-252$.

22. Hofman MS, Hicks RJ. Changing paradigms with molecular imaging of neuroendocrine tumors. Discov Med. 2012; 14:71-81.

23. Werner RA, Bluemel C, Allen-Auerbach MS, Higuchi T, Herrmann K. 68Gallium- and 90Yttrium-/ 177Lutetium: "theranostic twins" for diagnosis and treatment of NETs. Ann Nucl Med. 2015; 29:1-7.

24. DeNardo DA, DeNardo GL, Yuan A, Shen S, DeNardo SJ, Macey DJ, Lamborn KR, Mahe M, Groch MW, Erwin WD. Prediction of radiation doses from therapy using tracer studies with iodine-131-labeled antibodies. J Nucl Med. 1996; 37:1970-1975.

25. Fielder SE. Weight to Body Surface Area Conversion for Dogs. Merck Veterinary Manual.

26. Tabernero J, Pfeiffer P, Cervantes A. Administration of cetuximab every 2 weeks in the treatment of metastatic colorectal cancer: an effective, more convenient alternative to weekly administration? Oncologist. 2008; 13:113-119.

27. Ping Li W, Meyer LA, Capretto DA, Sherman CD, Anderson CJ. Receptor-binding, biodistribution, and metabolism studies of 64Cu-DOTA-cetuximab, a PETimaging agent for epidermal growth-factor receptor-positive tumors. Cancer Biother Radiopharm. 2008; 23:158-171.

28. Tinianow JN, Pandya DN, Pailloux SL, Ogasawara A, Vanderbilt AN, Gill HS, Williams SP, Wadas TJ, Magda D, Marik J. Evaluation of a 3-hydroxypyridin-2-one (2,3-HOPO) based macrocyclic chelator for (89) $\mathrm{Zr}(4+)$ and its use for immunoPET imaging of HER2 positive model of ovarian carcinoma in mice. Theranostics. 2016; 6:511-521.

29. Hassan BB, Elshafae SM, Supsavhad W, Simmons JK, Dirksen WP, Sokkar SM, Rosol TJ. Feline Mammary Cancer. Vet Pathol. 2017; 54:32-43.

30. Cho HS, Mason K, Ramyar KX, Stanley AM, Gabelli SB, Denney DW, Leahy DJ. Structure of the extracellular region of HER2 alone and in complex with the Herceptin Fab. Nature. 2003; 421:756-760. 